Journal Club

Editor's Note: These short, critical reviews of recent papers in the Journal, written exclusively by graduate students or postdoctoral fellows, are intended to summarize the important findings of the paper and provide additional insight and commentary. For more information on the format and purpose of the Journal Club, please see http://www.jneurosci.org/misc/ifa_features.shtml.

\title{
Spontaneous Functional Recovery from Incomplete Spinal Cord Injury
}

\author{
Rune Rasmussen ${ }^{1}$ and Eva Meier Carlsen ${ }^{2}$ \\ ${ }^{1}$ Center for Basic and Translational Neuroscience and ${ }^{2}$ Department of Neuroscience and Pharmacology, University of Copenhagen, Faculty of Health and \\ Medical Sciences, 2200 Copenhagen N, Denmark \\ Review of Hilton et al.
}

Our interactions with the world occur via precise coordination of our motor system. Even a movement as seemingly simple as reaching for an object is a complex motor behavior that requires precise neuronal activity in supraspinal areas (Lemon, 2008) and spinal areas (Azim et al., 2014). Motor cortical neurons projecting into the spinal cord via the corticospinal tract (CST) are involved in the preparation, execution, and adaptation of movements (Amos et al., 1990; Beloozerova and Sirota, 1993). Since the adult CNS has limited ability for regeneration, damage to the CST leads to motor deficits that typically persist throughout life (Schwab and Bartholdi, 1996; Raineteau and Schwab, 2001; Rosenzweig et al., 2010).

The columnar location of the CST varies across species (Armand, 1982; Lemon, 2008), and, while the main tract in humans is located in the middle part of the lateral column and a smaller tract in the ventral column, the main tract in rodents is located in the dorsal column, and smaller tracts are found both in the dorsolateral and ventral columns (Armand, 1982; Lemon, 2008). In rodents, the dor-

Received May 25, 2016; revised June 28, 2016; accepted June 29, 2016.

We thank J.-F. Perrier, N.A. Smith, and N.C. Petersen for valuable discussions and comments.

Correspondence should be addressed to Rune Rasmussen, Center for Basic and Translational Neuroscience, University of Copenhagen, Faculty of Health and Medical Sciences, 2200 Copenhagen N, Denmark. E-mail: runeras@sund.ku.dk.

DOI:10.1523/JNEUROSCI.1684-16.2016

Copyright $\odot 2016$ the authors $\quad 0270-6474 / 16 / 368535-03 \$ 15.00 / 0$ sal CST (dCST) is thought to mediate voluntary movements and spinal cord injury (SCI) damaging these CST axons results in pronounced motor deficits for all body parts below the lesion (Raineteau and Schwab, 2001; Hilton et al., 2013). Because the dorsolateral CST (dlCST) in general terminates in the same spinal areas as the dCST, this pathway may provide an alternative route for input to the spinal circuits when dCST axons are damaged (Steward et al., 2004).

SCIs are classified as complete or incomplete (Raineteau and Schwab, 2001); with a higher incidence of incomplete than complete SCIs in humans (Devivo, 2012). Following incomplete SCI, spontaneous functional recovery occurs in a sizable number of patients as well as in animal models, with time courses ranging from months to years (Raineteau and Schwab, 2001; Rosenzweig et al., 2010; Hilton et al., 2016). Nevertheless, the detailed mechanisms underlying spontaneous functional recovery are poorly understood. In particular, the extent to which recovery emerges from the regrowth of severed axons versus compensation by spared axons is unclear. In an article published in The Journal of Neuroscience, Hilton et al. (2016) investigated the role of spared dlCST neurons in functional recovery using optogenetic motor mapping and chemoreceptor-mediated neuronal inhibition in mice.

To mimic incomplete SCI, Hilton et al. (2016) used a surgical procedure that severs the dCST (containing $96 \%$ of CST axons) at the $\mathrm{C} 3 / \mathrm{C} 4$ level of the spinal cord, leaving the dlCST (3\%) and ventral CST (1\%) intact. Spinal cord-injured mice exhibited substantial motor deficits when walking on a horizontal ladder soon after injury, but error rates were markedly reduced $56 \mathrm{~d}$ after injury, suggesting spontaneous functional recovery. Interestingly, there was a clear difference in recovery between forelimbs and hindlimbs: on day 58, the forelimb function had only partially recovered, whereas the hindlimb had fully recovered by $\mathrm{d} 7$ after injury. Similarly, incomplete SCI resulted in twice as many forelimb than hindlimb errors on the ladder right after injury.

This discrepancy in forelimb versus hindlimb recovery may appear surprising, as incomplete cervical SCIs are often considered the most detrimental type of incomplete SCI, because of its equally devastating impact on arm and leg motor function, often leading to quadriplegia in humans (Bjørnshave Noe et al., 2015). However, similar findings have been shown in rats (Filli et al., 2011). This suggests that skilled forelimb motor function relies more on dCST input than hindlimb motor function does. This explanation seems reasonable when considering the high diversity in skilled movement repertoire of forelimbs in rodents, which includes reaching and grasping (Azim et al. 2014). Alternatively, the difference in forelimb versus hindlimb recovery may originate from local spinal damage and inflammation occurring near the injury site, which was closer to forelimb than 
hindlimb motor circuits (Lemon, 2008; Hilton et al., 2013).

To investigate whether motor cortical plasticity occurs during spontaneous functional recovery, Hilton et al. (2016) used optogenetic excitation of channelrhodopsin-2-expressing excitatory neurons in layer $\mathrm{V}$ of the motor cortex to map areas that produce limb movements. Because the excitation of neurons was triggered by light, as opposed to classic electrical stimulation, motor mapping could be performed through a chronic cranial window. This allowed the authors to monitor cortical changes over a period of weeks following SCI. Unsurprisingly, just after injury, both motor output and cortical map area were significantly reduced for both forelimbs and hindlimbs. These measures re-established over time: 3 weeks after SCI, both forelimb motor output and map area had recovered. Interestingly, comparing the time course of motor mapping recovery with the functional performance on the horizontal ladder revealed important differences. At day 21 postinjury, all of the evaluated forelimb motor mapping measures had been reestablished, although forelimb motor performance on the ladder appeared no better than right after SCI. This discrepancy between motor mapping and functional performance suggests that direct activation of the CST in anesthetized mice cannot fully assess spontaneous functional recovery, and therefore other neuronal circuits must be involved. One shortcoming of motor mapping is the bypassing of somatosensory feedback in the assessment of motor function. The ability to perform skilled movements requires processing and forwarding of somatosensory information from multiple areas, including spinal cord, cerebellum, and somatosensory cortex (Lemon, 2008; Manto et al., 2012; Faraji et al., 2013). In the present experiments, the dorsal column sensory afferents were bilaterally severed, resulting in a substantial loss of somatosensory feedback. Such feedback has been shown to affect motor cortical excitability and functional motor abilities in humans (Rothwell et al., 1982; Roy et al., 2010). We speculate that the discrepancy between motor mapping and functional motor performance might be explained, at least partly, by a lack of incoming somatosensory feedback to the motor cortex during movement. This would result in the disturbance of sensorimotor integration and execution of skilled movements on the horizontal ladder without affecting motor mapping.

A key experimental question posed by Hilton et al. (2016) was whether spontaneous functional recovery following dorsal
SCI is mediated primarily by spared or severed CST neurons. To answer this, the authors selectively expressed inhibitory $\mathrm{G}_{\mathrm{i}}$-coupled designer receptors exclusively activated by designer drugs (DREADDs) in spared dlCST neurons. By activating the DREADDs, with the inert ligand clozapine$\mathrm{N}$-oxide (CNO), they selectively suppressed dlCST neurons in mice recovering from dorsal SCI. Administering CNO reversibly increased the forelimb error rate on the horizontal ladder at days 56 and 58 after SCI, providing evidence that activity of spared dlCST neurons is involved in spontaneous functional recovery. Unfortunately, the authors did not combine $\mathrm{CNO}$-induced neuronal inhibition with optogenetic motor mapping in control mice. Such an experiment would have demonstrated the degree to which DREADD activation suppresses CST neurons, and how this interferes with motor output in noninjured mice. This would have been a refined way of validating the inhibitory effect of DREADD activation, supplementing the decreased c-Fos staining shown. Another experiment of potentially even more interest would have been to suppress dlCST neurons using DREADDs on day 58 after SCI, in combination with optogenetic motor mapping. This would have allowed the authors to causally link motor map changes with the activity of dlCST neurons. If map re-establishment primarily resulted from changes and reorganization of dlCST neurons, suppressing these would likely have produced a motor map similar to the map observed right after injury. Conversely, if suppressing dlCST neurons did not affect the motor map, this would indicate that these neurons were not causally involved in the re-establishment of the motor map. Instead, this might result from collateral regrowth or sprouting of severed dCST neurons (Bernstein and Bernstein, 1971). One experiment that could investigate whether severed dCST axons regrow, would be to retrogradely label CSTs when functional recovery has developed, and compare dorsal labeling to labeling occurring shortly after SCI. Any dCST labeling after functional recovery would indicate that severed axons had regrown and could be involved in motor map re-establishment.

One possibility is that the changes occurring in dlCST neurons mediating spontaneous functional recovery develop during a critical period following SCI, potentially representing a window of opportunity for rehabilitation strategies. A recent study in humans (Herzer et al. 2016) showed that earlier rehabilitation following SCI was positively correlated with improved functional outcome 1 year after SCI. Whether a window of opportunity for dlCST plasticity causally explains this relationship is currently unknown. This could be investigated by suppressing spared CST neurons during the acute phase, and evaluate whether that affects subsequent functional motor recovery. Results from such experiments would potentially provide a mechanistic rationale for initiating rehabilitation as soon as possible after SCI to boost processes mediating functional recovery.

In summary, by applying advanced techniques, the work by Hilton et al. (2016) showed that, although comprising only 3\% of CST axons, the spared dlCST axons that remain intact after dorsal SCI are crucial for spontaneous functional recovery. This study paves the way for future research aiming at investigating the detailed neurophysiological mechanisms underlying functional recovery after SCI, as well as for revealing critical periods for maximizing plastic changes and recovery prospects for individuals experiencing incomplete SCI.

\section{References}

Amos A, Armstrong DM, Marple-Horvat DE (1990) Changes in the discharge patterns of motor cortical neurones associated with volitional changes in stepping in the cat. Neurosci Lett 109:107-112. CrossRef Medline

Armand J (1982) The origin, course and terminations of corticospinal fibers in various mammals. Prog Brain Res 57:329-360. CrossRef Medline

Azim E, Jiang J, Alstermark B, Jessell TM (2014) Skilled reaching relies on a V2a propriospinal internal copy circuit. Nature 508:357-363. CrossRef Medline

Beloozerova IN, Sirota MG (1993) The role of the motor cortex in the control of accuracy of locomotor movements in the cat. J Physiol 461:1-25. CrossRef Medline

Bernstein JJ, Bernstein ME (1971) Axonal regeneration and formation of synapses proximal to the site of lesion following hemisection of the rat spinal cord. Exp Neurol 30:336-351. CrossRef Medline

Bjørnshave Noe B, Mikkelsen EM, Hansen RM, Thygesen M, Hagen EM (2015) Incidence of traumatic spinal cord injury in Denmark, 1990-2012: a hospital-based study. Spinal Cord 53:436-440. CrossRef Medline

Devivo MJ (2012) Epidemiology of traumatic spinal cord injury: trends and future implications. Spinal Cord 50:365-372. CrossRef Medline

Faraji J, Gomez-Palacio-Schjetnan A, Luczak A, Metz GA (2013) Beyond the silence: bilateral somatosensory stimulation enhances skilled movement quality and neural density in intact behaving rats. Behav Brain Res 253:78-89. CrossRef Medline

Filli L, Zörner B, Weinmann O, Schwab ME (2011) Motor deficits and recovery in rats with unilateral spinal cord hemisection mimic the Brown-Sequard syndrome. Brain 134: 2261-2273. CrossRef Medline 
Herzer KR, Chen Y, Heinemann AW, GonzálezFernández M (2016) Association between time-to-rehabilitation and outcomes following traumatic spinal cord injury. Arch Phys Med Rehabil. Advance online publication. Retrieved July 4, 2016. doi:10.1016/ j.apmr.2016.05.009. CrossRef Medline

Hilton BJ, Assinck P, Duncan GJ, Lu D, Lo S, Tetzlaff W (2013) Dorsolateral funiculus lesioning of the mouse cervical spinal cord at $\mathrm{C} 4$ but not at C6 results in sustained forelimb motor deficits. J Neurotrauma 30:1070-1083. CrossRef Medline

Hilton BJ, Anenberg E, Harrison TC, Boyd JD, Murphy TH, Tetzlaff W (2016) Re-establishment of cortical motor output maps and spontaneous functional recovery via spared dorsolaterally projecting corticospinal neurons after dorsal column spinal cord injury in adult mice. J Neurosci 36: 4080-4092. CrossRef Medline

Lemon RN (2008) Descending pathways in mo- tor control. Annu Rev Neurosci 31:195-218. CrossRef Medline

Manto M, Bower JM, Conforto AB, DelgadoGarcía JM, da Guarda SN, Gerwig M, Habas C, Hagura N, Ivry RB, Mariën P, Molinari M, Naito E, Nowak DA, Oulad Ben Taib N, Pelisson D, Tesche CD, Tilikete C, Timmann D (2012) Consensus paper: roles of the cerebellum in motor control-the diversity of ideas on cerebellar involvement in movement. Cerebellum 11:457-487. CrossRef Medline

Raineteau O, Schwab ME (2001) Plasticity of motor systems after incomplete spinal cord injury. Nat Rev Neurosci 2:263-273. CrossRef Medline

Rosenzweig ES, Courtine G, Jindrich DL, Brock JH, Ferguson AR, Strand SC, Nout YS, Roy RR, Miller DM, Beattie MS, Havton LA, Bresnahan JC, Edgerton VR, Tuszynski MH (2010) Extensive spontaneous plasticity of corticospinal projections after primate spinal cord injury. Nat Neurosci 13:1505-1510. CrossRef Medline

Rothwell JC, Traub MM, Day BL, Obeso JA, Thomas PK, Marsden CD (1982) Manual motor performance in a deafferented man. Brain 105:515-542. CrossRef Medline

Roy FD, Yang JF, Gorassini MA (2010) Afferent regulation of leg motor cortex excitability after incomplete spinal cord injury. J Neurophysiol 103:2222-2233. CrossRef Medline

Schwab ME, Bartholdi D (1996) Degeneration and regeneration of axons in the lesioned spinal cord. Physiol Rev 76:319-370. Medline

Steward O, Zheng B, Ho C, Anderson K, TessierLavigne M (2004) The dorsolateral corticospinal tract in mice: an alternative route for corticospinal input to caudal segments following dorsal column lesions. J Comp Neurol 472:463-477. CrossRef Medline 